\title{
EHMTI-0327. Information and communication technology for improving the management of medication overuse headache: results of the comoestas multicentric, multinational study
}

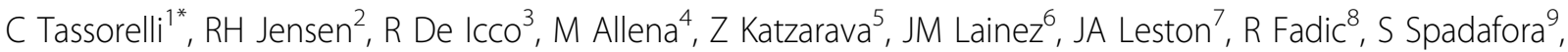 \\ M Pagani ${ }^{10}$, N Giuseppe $^{4}$
}

From 4th European Headache and Migraine Trust International Congress: EHMTIC 2014

Copenhagen, Denmark. 18-21 September 2014

\section{Background}

The management of medication overuse headache $(\mathrm{MOH})$ is rewarding but also challenging because effective treatment is frequently followed by relapses. Information and Communication Technology has recently been proposed as a valid aid to improve healthcare quality in chronic conditions. In this frame, we developed a headache diary associated with an alert/alarm logic for the interactive monitoring and the professional support of $\mathrm{MOH}$ patients after detoxification.

\begin{abstract}
Aim
Assessment of the acceptability and the effectiveness of this interactive monitoring system, in association with pharmacological treatment, on the outcome of $\mathrm{MOH}$ subjects.
\end{abstract}

\section{Methods}

A parallel-arm, single-blind study was conducted in 4 European Countries and 2 Latin-American Countries. A total of 499 subjects completed the study. Both Groups of patients underwent detoxification and were prescribed prophylactic medications (if required) at baseline. Subsequently, subjects in Group 1 were followed-up with a paper diary and periodical visits for a period of 6 months, while subjects in Group 2 were followed-up with the interactive monitoring system for the same length of time.

\section{Results}

We observed a highly significant improvement of most outcome parameters in both Groups. However, subjects in Group 2 presented a significantly higher percentage of cured cases $(92.4 \%$ vs $83.3 \%, \mathrm{p}<0.001)$, a lower rate of relapsers $(6.2 \%$ vs $9.1 \%, \mathrm{p}<0.003)$ and an improved patient satisfaction $(8.4+1.7$ vs $6.9+1.9, \mathrm{p}<0.05)$.

\section{Conclusions}

Adoption of an interactive monitoring system is well accepted by $\mathrm{MOH}$ patients and it is associated to a more favorable outcome after detoxification. (EC FP7, contract number 215366).

No conflict of interest.

\footnotetext{
Authors' details

${ }^{1}$ Headache Science Centre Dept. of Brain and Behavioural Sciences, C. Mondino National Neurological Institute and University of Pavia, Pavia, Italy. ${ }^{2}$ Danish Headache Centre Dept. of Neurology, Glostrup Hospital Faculty of Health Sciences University of Copenhagen, Copenhagen, Denmark. ${ }^{3}$ Headache Science Centre Dept of Brain and Behavioural Sciences, C. Mondino National Neurological Institute and University of Pavia, Pavia, Italy. ${ }^{4}$ Headache Science Centre, C. Mondino National Neurological Institute, Pavia, Italy. ${ }^{5}$ Dept. of Neurology, University of Essen, Essen, Germany. ${ }^{6}$ Foundation of the Valencian Community, University Clinical Hospital, Valencia, Spain. ${ }^{7}$ Headache Centre, Foundation for Combating Neurological Diseases of Childhood, Buenos Aires, Argentina. ${ }^{8}$ Dept. of Neurology, Pontificia Catolica University of Chile, Santiago, Chile. ${ }^{9}$ Medical Informatics, ISalud University, Buenos Aires, Argentina. ${ }^{10}$ Directorate, Bioengeneering and Medical Informatics Consortium, Pavia, Italy.
} 
doi:10.1186/1129-2377-15-S1-D63

Cite this article as: Tassorelli et al:: EHMTI-0327. Information and communication technology for improving the management of medication overuse headache: results of the comoestas

multicentric, multinational study. The Journal of Headache and Pain 2014 15(Suppl 1):D63.

\section{Submit your manuscript to a SpringerOpen ${ }^{\mathcal{D}}$ journal and benefit from:}

- Convenient online submission

- Rigorous peer review

- Immediate publication on acceptance

- Open access: articles freely available online

- High visibility within the field

- Retaining the copyright to your article

Submit your next manuscript at $\gg$ springeropen.com 